\title{
Lung cancer mortality and radon exposure in Russia
}

Ilia V. Yarmoshenko, Georgy P. Malinovsky

\begin{abstract}
$\overline{\text { Abstract. The association between the lung cancer and indoor radon exposure in Russian population was }}$ investigated. The average indoor radon concentration for each region was estimated using the annual reports issued by the Saint-Petersburg Ramzaev Research Institute of Radiation Hygiene for the period 2008-2013. The average standardized lung cancer mortalities among males and females were estimated using the reports of the Moscow Hertzen Cancer Research Institute for the period 2008-2012. The relative risk (RR) was estimated as a ratio between the average mortality within seven exposure intervals and background mortality. The slope factors of linear dependence between the indoor radon exposure and lung cancer RR are $0.026(-0.11 \div 0.17)$ and $0.83(0.52-1.12)$ per radon concentration $100 \mathrm{~Bq} / \mathrm{m}^{3}$ for males and females, respectively (with $90 \%$ confidence interval). The obtained results can be explained by the confounding effect of tobacco smoking. Significant excess risk of lung cancer in female population can be associated with radon exposure and low prevalence of smoking.
\end{abstract}

Key words: lung cancer $\bullet$ radon $\bullet$ relative risk $\bullet$ smoking

I. V. Yarmoshenko ${ }^{\bowtie}$, G. P. Malinovsky Institute of Industrial Ecology UB RAS, 20 Sophy Kovalevskoy Str., Ekaterinburg 620219, Russia,

Tel.: +7 343 3623393, Fax: +7 343 3743771,

E-mail: ivy@ecko.uran.ru

Received: 24 November 2015

Accepted: 23 March 2016

\section{Introduction}

Cohort studies of uranium miners and case control studies of indoor radon and lung cancer conducted in the recent decades have provided strong evidence that radon exposure causes lung cancer [1]. The epidemiological observations of uranium miners in the 1980s and 1990s revealed lung cancer as the main health effect associated with radon progeny inhalation. According to the joint analysis of 11 cohort studies performed by Lubin et al. [2], the risk of lung cancer depends on the radon exposure with regard to either rate of exposure or duration of exposure the following factors modify the risk as well: sex, time since exposure, age at the beginning of exposure, and attained age. A comparison of detriment due to radon exposure of miners with known health effects of whole body external exposure (life-span study of A-bomb survivors [3] and other studies) was applied to estimate the dose coefficient using the conversion convection [4]. While the findings of miners' cohort studies were obtained for an exposure range higher than the indoor radon levels, radon-induced risks for population were estimated by extrapolation of miners data to the range of low radon concentration.

Later, a case-control design of the epidemiological analysis was applied to investigate lung cancer risks due to indoor radon exposure. The main advantages of case-control and cohort studies are as follows: 
- individual data on radon exposure (both concentration and duration),

- individual data on smoking,

- individual data on other carcinogens,

- possibility to perform meta-analysis and pooling analysis.

At the same, it appeared that a single case-control residential study has insufficient statistical power to obtain reliable results on the risk of radon-induced health effects. The point estimates of excess relative risk (ERR) of lung cancer were both negative and positive in different studies, while 95\% confidential intervals included negative and positive values in all studies. However, the meta-analyses of published data have produced significant ERR $>1$ at a relatively low indoor radon concentration [5-7]. The most reliable data on lung cancer risk associated with indoor radon were gained after pooling analysis of residential studies, which utilizes the advantages of case-control type of study and provides higher statistical power. According to the pooling of European residential case-control studies, $\mathrm{ERR}=1.16(95 \%$ confidence interval 1.05-1.31) at radon concentration $100 \mathrm{~Bq} / \mathrm{m}^{3}$ [8]. Basing on the pooling analyses of residential studies in Europe and Northern America [9], WHO concluded that radon is second after smoking cause of lung cancer in general population [10]. ICRP considered these results as reliable arguments for justification of protection strategy and a basis for establishing the national-derived reference levels of the indoor radon concentration below $300 \mathrm{~Bq} / \mathrm{m}^{3}[1,11]$.

Another type of study of the dose-effect relationship is ecological or geographical correlation one. This type is cheap and rapid. It allows generalization, exploration of time trends, and generating of hypothesis. But, there are strong limitations associated with the aggregated data. The use of standard epidemiological precautions is necessary when interpreting the results of the ecological study.

The most cited ecological study was conducted by Cohen in the USA [12]. Cohen estimated the correlation between the average indoor radon concentration and lung cancer mortality in 1601 USA counties and found a strong negative dependence. The findings of this study that contradict to the dose-effect relationship observed among the miners provoked remarkable scientific discussion. Most of specialists criticized the design of ecological study, which is unable to account for individual smoking status $[7,13]$. Thoroughly evaluating all epidemiological data, UNSCEAR and ICRP concluded that there is a strong scientific base to apply linear non-threshold dependence (LNTD) for lung cancer risk and indoor radon exposure $[1,7]$.

In the last decades in Russia, considerable progress was achieved in indoor radon measurements. The measurements of radon concentration at homes are conducted in most of regions of the country. More than 400 measurements are performed in the half of the 83 regions annually. The total number of indoor radon EEC measurements amounts to several hundreds of thousands. The level of medical care ensures reliable diagnosing of lung cancer cases and medical statistic recording as well. Thus, it is possible to compare lung cancer mortality and indoor radon by regions of Russia, using the ecological design study. Such analysis is not intended to test LNTD, while individual control of smoking could not be enabled. On the contrary, the aim is to investigate the confounding effect of smoking in the ecological study. The results of the ecological study in Russia are compared with the results of pooling analysis of European residential case-control studies as well.

\section{Materials and methods}

The average indoor radon concentration in each region of Russia was reconstructed basing on the data in the Integrated State System for Doses Control and Registration - so-called Form DOZ Number 4. This form is included in the annual reports issued by the Saint-Petersburg Institute of Radiation Hygiene [14-19]. An annual report for each region provides the value of average indoor radon equilibrium equivalent concentration and the number of measurements by three main type of buildings: wooden house, one-storey stone house (constructed using stone, brick, concrete, and so on), and multi-storey stone house. Totally, information of more than 400000 measurements of indoor radon equivalent equilibrium concentration in 83 regions of Russia was used. The standardization of radon measurements is ensured by meeting the requirements of the state metrological system. According to the estimations, the radon concentration lies in the range from 20 to $80 \mathrm{~Bq} / \mathrm{m}^{3}$ in most of the regions, and the average indoor radon concentration in Russia is $48 \mathrm{~Bq} / \mathrm{m}^{3}$. In more detail, the approach to reconstruction of national distribution of indoor radon concentration in Russia is presented in [20]. The regional average radon concentrations are presented in Table 1 and their distribution is shown in Fig. 1.

Information on malignant neoplasm in Russia is collected by the Moscow Hertzen Cancer Research Institute, which issues its reports annually as well [21-25]. The regional 5-year average standardized lung cancer mortality of females and males is presented in Table 1 and its distribution is shown in

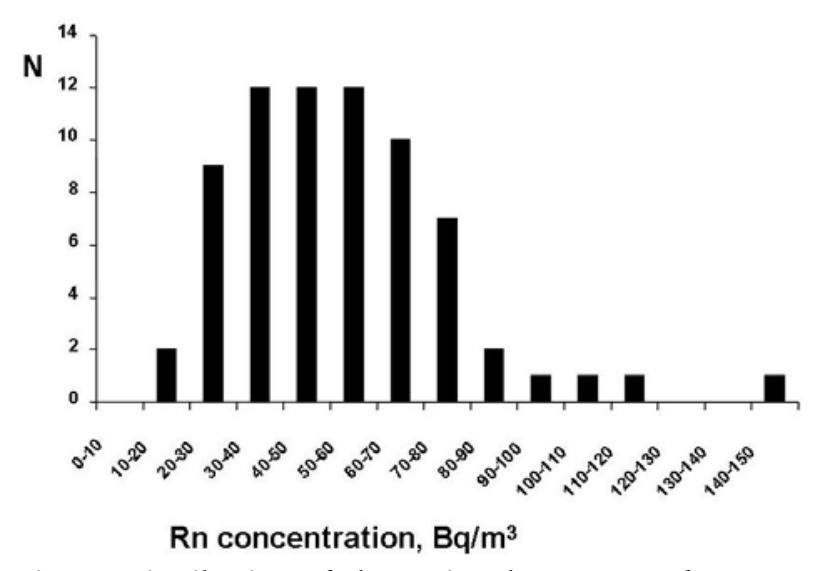

Fig. 1. Distribution of the regional average radon concentration. 


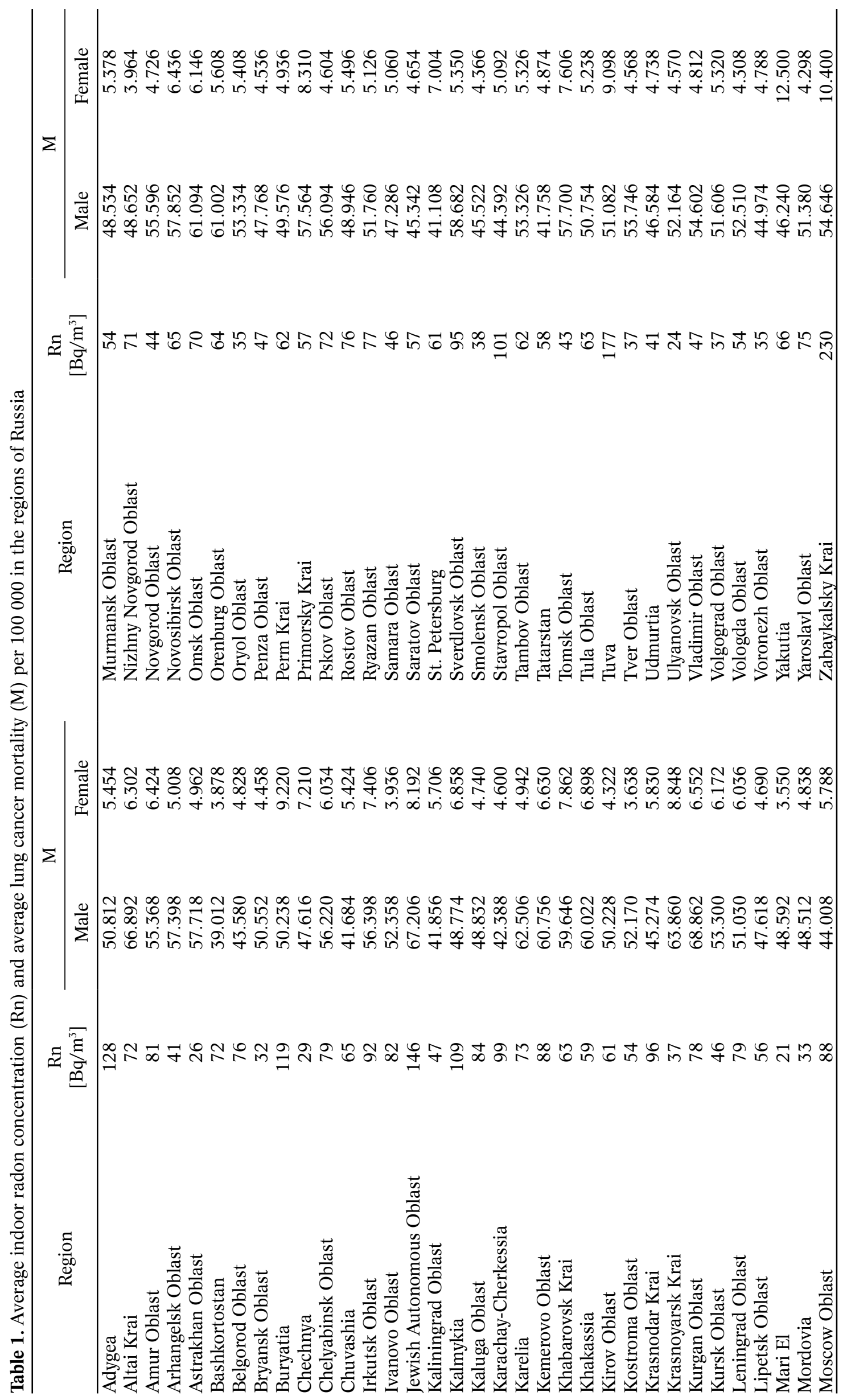




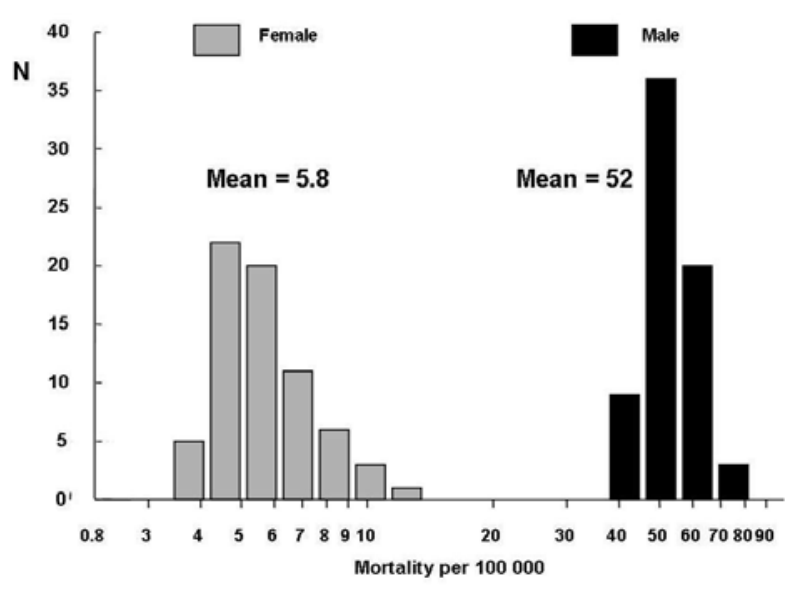

Fig. 2. Distribution of the regional annual lung cancer mortality.

Fig. 2. The difference between males and females is large - order of magnitude. The mean value is 52 per 100000 males and 5.8 per 100000 females.

Due to remarkable climatic and socio-economic inconsistency with other regions of Russia, some arctic regions, mountain regions, and capital city were excluded from the analysis: Dagestan, Kamchatka Krai, Altai Republic, Komi Republic, Sakhalin Oblast, North Ossetia, Tyumen Oblast, Khanty-Mansi Autonomous Okrug, Chukotka Autonomous Okrug, Yamalo-Nenets Autonomous Okrug, Magadan Oblast, and Moscow.

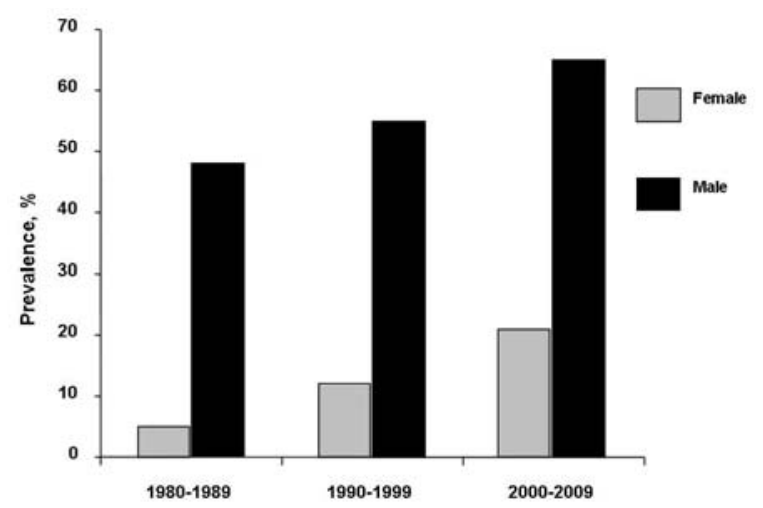

Fig. 3. Tobacco use prevalence in Russia according to [26].

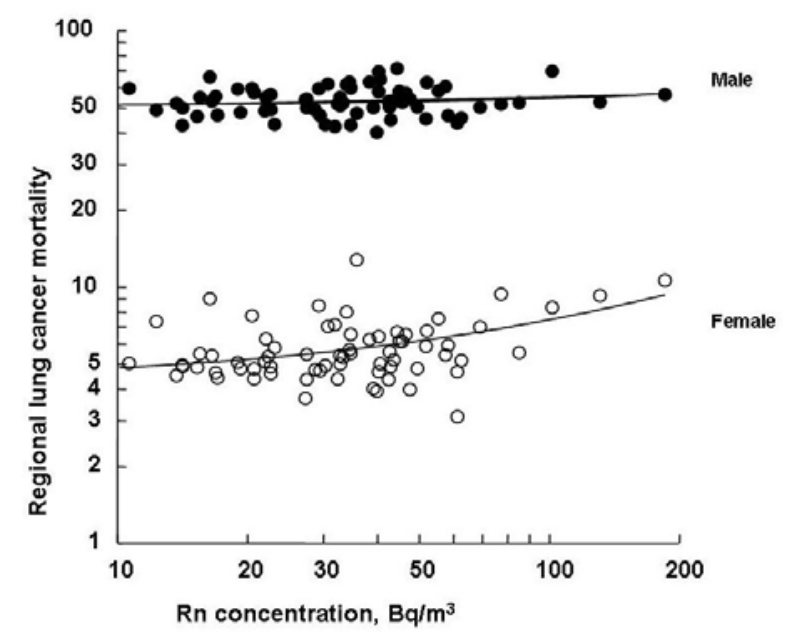

Fig. 4. The regional lung cancer mortality vs. the average regional radon concentration.
Information of tobacco smoking in the Russian population was obtained from the results of the Global Adult Tobacco Survey [26] conducted in Russia in 2009. The tobacco use prevalence in Russia in periods 1980-1989, 1990-1999, 2000-2009 for males and females are presented in Fig. 3.

The relative risk (RR) of lung cancer was estimated as a ratio between the observed mortality and mortality expected for zero indoor radon concentration. To analyse the dependence of ERR = RR- 1 on exposure, the regional indoor radon concentration estimated using an equilibrium factor 0.4 were divided into seven intervals: $<37,37-46,47-58$, $59-65,66-76,77-95$, and $>95 \mathrm{~Bq} / \mathrm{m}^{3}$. Each interval contains $8-10$ values.

\section{Results}

Dependences between 5-year average lung cancer mortalities among males and females and the regional average indoor radon concentration are presented in Fig. 4. A simple linear model is applied to fit the observed relationship:

$$
\mathrm{M}(\mathrm{Rn})=\mathrm{M}_{0}+b \cdot \mathrm{Rn},
$$

where, $\mathrm{M}(\mathrm{Rn})$ is the observed mortality (per $10^{5}$ ) at the indoor radon concentration $\mathrm{Rn}\left[\mathrm{Bq} / \mathrm{m}^{3}\right] ; \mathrm{M}_{0}$ is the intercept factor equal to mortality at $\mathrm{Rn}=0$ (per $\left.10^{5}\right) ; b$ is the slope factor of linear dependence, $10^{-4} /\left(\mathrm{Bq} / \mathrm{m}^{3}\right)$.

A positive significant correlation between the indoor radon and lung cancer was found for the female population, while for males, it appeared insignificant (Table 2).

For further analysis, we estimated the RR as a ratio between the observed mortality and mortality estimated for zero indoor radon concentration $\left(\mathrm{RR}=\mathrm{M} / \mathrm{M}_{0}\right)$. The estimated values of $\mathrm{RR}$ for seven intervals of the indoor radon concentrations with 90\% confidence interval are presented in Fig. 5 for females and males, respectively. The $90 \%$ confidence interval for RR is estimated taking into account both variation of $\mathrm{M}$ within the intervals of the radon concentration and $\mathrm{M}_{0}$. The dependence of RR on the average indoor radon concentration in the intervals is fitted using the following model equation:

$$
\mathrm{RR}=1+B \cdot \mathrm{Rn},
$$

where, the risk coefficient $B=0.52(0.27-0.77)$ per $100 \mathrm{~Bq} / \mathrm{m}^{3}$ and $0.03(-0.06 \div 0.13)$ per $100 \mathrm{~Bq} / \mathrm{m}^{3}$ for females and males, respectively (with $90 \%$ confidence intervals).

Table 2. Coefficients of linear regression between the regional lung cancer mortality and the average regional indoor radon concentration

\begin{tabular}{lcc}
\hline & $\mathrm{M}_{0}$ & $b \cdot 100$ \\
& & {$\left[\mathrm{~Bq} / \mathrm{m}^{3}\right]$} \\
\hline Male & $50 \pm 4$ & $2.1 \pm 5.7$ \\
Female & $4.3 \pm 0.7$ & $2.4 \pm 1.2$ \\
\hline
\end{tabular}



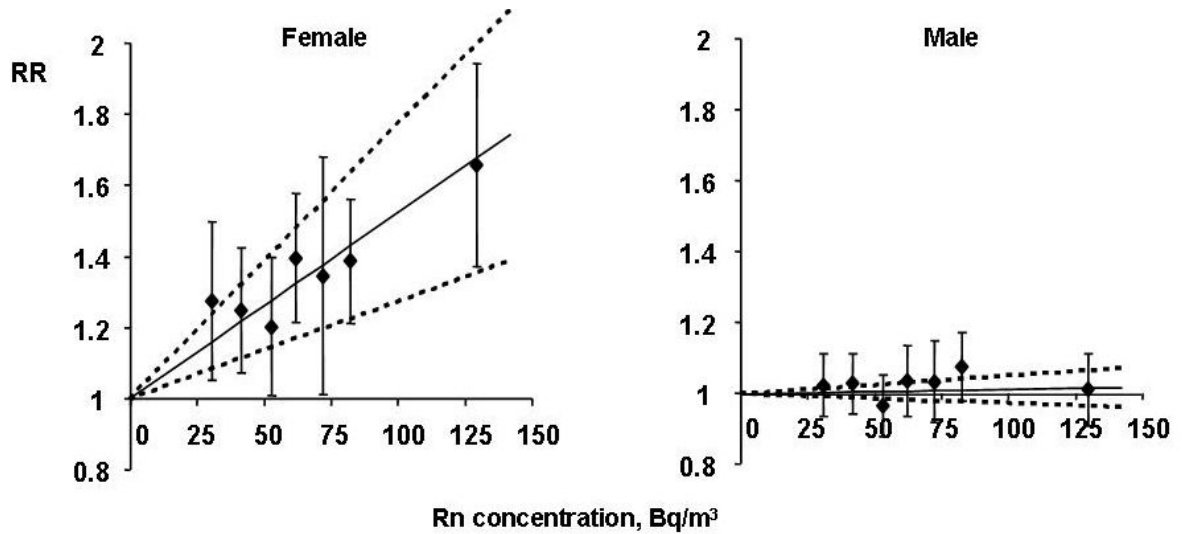

Fig. 5. Relative risk vs. radon concentration.

\section{Discussion}

The results of the ecological study should be analysed taking into account the confounding effect of tobacco smoking. To analyse the influence of smoking, we applied the results of the Global Adult Tobacco Survey [26] conducted in Russia in 2009 (Fig. 3). As can be seen in the figure, the prevalence of smoking among males is very high - above $50 \%$. Female smoking rises during 30 years from 5 to $20 \%$. It is necessary to note that 20 years before 2009, the smoking prevalence among women was relatively low in Russia.

We suppose that the risk of lung cancer induced by indoor radon exposure can be hidden behind the confounding effect of tobacco smoking. Consequently, a possibility to obtain significant RR associated with radon is higher when tobacco smoking is lower. The effect of radon exposure in females appears under low prevalence of the smoking in the Russian female population 20 years before. Taking into account 10-20 years latent period for lung cancer, the contribution of smoking to female lung cancer mortality in Russia in period from 2009 to 2012 is expected to be low by an absolute value and considerably lower than the contribution to the lung cancer mortality in males. The effect of radon exposure of male population of Russia cannot be found due to the high level of tobacco smoking between males.

The results of the geographical correlated analysis of indoor radon and lung cancer in the Russian regions are compared with the pooling of European case-control study performed by Sarah Darby with

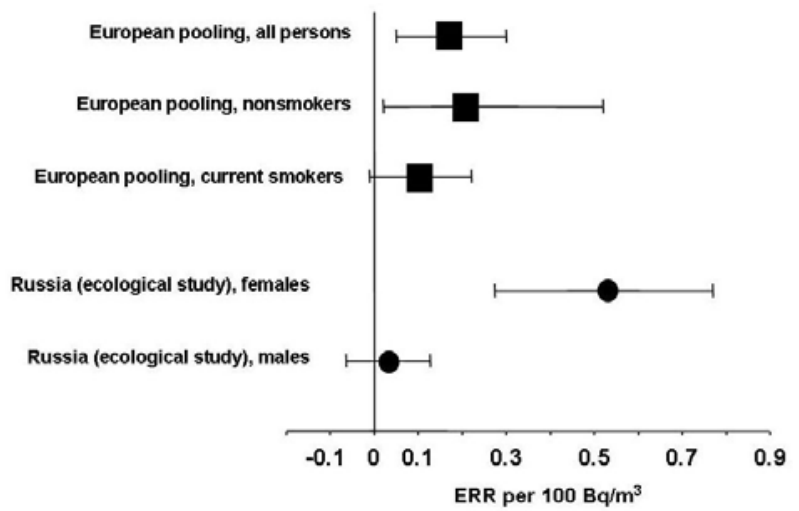

Fig. 6. Excess RR per $100 \mathrm{~Bq} / \mathrm{m}^{3}$ (European pooling - after correction for uncertainties [8]). colleagues [8]. Figure 6 shows the estimations of ERR per $100 \mathrm{~Bq} / \mathrm{m}^{3}$ obtained in the pooling analysis for all persons - mixture of smokers and non-smokers, and our results for females and males. The tendency for higher radon-induced risk for low-smoking population can be suggested from the comparison of Russian female data and European mixture population. It may result in underestimation of risk for the low-smoking population. The higher value of ERR for Russian female low smoking population may relate to different radon-induced ERR for smokers and non-smokers. The results of ERR estimations for smokers in the European pooling study and for high-smoking Russian males can be considered similar. However, the central estimation of ERR in European pooling is higher that can be associated with the application of individual data on smoking in the analysis.

Comparing ERR obtained in the European poling for mixture of males and females, smokers and non-smokers, and the result of ecological study in Russia suggests that ERR from the pooling analysis of case-control studies can be accepted for radon risk estimations in Russia. Such estimation is necessary for justification of protection against radon exposure at home.

\section{Conclusion}

The general conclusions of the study are as follows:

- Assessment of lung cancer risk induction due to indoor radon exposure in Russia can be based on the results of pooled analysis of European case-control studies.

- Unusual proportion of smokers and non-smokers in male and female population is a significant source of uncertainty for risk projection.

- Interaction with smoking is still a challenging research task.

\section{References}

1. ICRP. (2010). Lung cancer risk from radon and progeny and statement on radon. (ICRP Publication 115). Ann. ICRP, 40(1).

2. Lubin, J. H., Boice, J. D., Edling, C., Hornung, R. W., Howe, G., Kunz, E., Kusiak, R. A., Morrison, H. I., Radford, E. P., Samet, J. M., Tirmarche, M., 
Woodward, A., Xiang, Y. S., \& Pierce, D. A. (1994). Radon and lung cancer risk: A joint analysis of 11 underground miner studies. Bethesda, MD: U.S. Department of Health and Human Services, Public Health Service, National Institutes of Health. (NIH Publication no. 94-3644)

3. Preston, D. L., Shimizu, Y., Pierce, D. A., Suyama, A., \& Mabuchi, K. (2003). Studies of mortality of atomic bomb survivors. Report 13: Solid cancer and noncancer disease mortality: 1950-1997. Radiat. Res., 160, 381-407.

4. ICRP. (1993). Protection against radon-222 at home and at work. (ICRP Publication 65). Ann. ICRP, 23(2).

5. Lubin, J. H., \& Boice Jr, J. D. (1997). Lung cancer risk from residential radon: meta-analysis of eight epidemiologic studies. J. Natl. Cancer Inst., 89, 49-57.

6. Yarmoshenko, I. V., Kirdin, I. A., Zhukovsky, M. V., \& Astrakhantseva, S. Y. (2005). Meta-analysis of twenty radon and lung cancer case control studies. Radioact. Environ., 7, 762-771.

7. UNSCEAR. (2009). UNSCEAR 2006 Report. Annex E. Sources-to-effects assessment for radon in homes and workplaces. New York: UN.

8. Darby, S., Hill, D., Auvinen, A., Barros-Dios, J. M., Baysson, H., Bochicchio, F., Deo, H., Falk, R., Forastiere, F., Hakama, M., Heid, I., Kreienbrock, L., Kreuzer, M., Lagarde, F., Mäkeläinen, I., Muirhead, C., Oberaigner, W., Pershagen, G., Ruano-Ravina, A., Ruosteenoja, E., Schaffrath Rosario, A., Tirmarche, M., Tomášek, L., Whitley, E., Wichmann, H. E., \& Doll, R. (2005). Radon in homes and risk of lung cancer: collaborative analysis of individual data from 13 European case-control studies. Br. Med. I., 330(7485), 223-227.

9. Krewski, D., Lubin, J. H., Zielinski, J. M., Alavanja, M., Catalan, V. S., Field, R. W., Klotz, J. B., Létourneau, E. G., Lynch, C. F., Lyon, J. I., Sandler, D. P., Schoenberg, J. B., Steck, D. J., Stolwijk, J. A., Weinberg, C., \& Wilcox, H. B. (2005). Residential radon and risk of lung cancer. A combined analysis of 7 North American case-control studies. Epidemiology, 16(2), 137-145.

10. World Health Organization. (2009). WHO Handbook on indoor radon: A public health perspective. Geneva: WHO Press.

11. ICRP. (2014). Radiological protection against radon exposure. (ICRP Publication 126). Ann. ICRP, 43(3).

12. Cohen, B. L. (1995). Test of the linear-no threshold theory of radiation carcinogenesis for inhaled radon decay products. Health Phys., 68(2), 157-174.

13. Puskin, J. S. (2003). Smoking as a confounder in ecologic correlations of cancer mortality rates with average county radon levels. Health Phys., 84(4), 526-532.
14. ISSDCR. (2009). Results of unified system of individual dose control functioning during 2008. Radiat. Hyg., 4(2), 46-67 (in Russian).

15. ISSDCR. (2011). Results of functioning of the integrated state system for doses control and registration (ESKID) according to the data for 2009. Radiat. Hyg., 1(4), 55-77 (in Russian).

16. ISSDCR. (2011). Integrated state system for doses control and registration (Forms No. 3-DOZ and No. 4-DOZ) on the basis of 2010 data. Radiat. Hyg., 4(4), 51-69 (in Russian).

17. ISSDCR. (2012). Integrated state system for doses control and registration (Form no. 4-DOZ) on the basis of 2011 data. Radiat. Hyg., 3(5), 68-76 (in Russian).

18. ISSDCR. (2013). Integrated state system for doses control and registration (Forms No. 1-DOS, No. 3-DOS and No. 4-DOS) on the basis of 2012 data. Radiat. Hyg., 3(6), 63-86 (in Russian).

19. ISSDCR. (2014). Integrated state system for doses control and registration (Forms No. 1-DOS, No. 3-DOS and No. 4-DOS) on the basis of 2013 data. Radiat. Hyg., 3(7), 54-81 (in Russian).

20. Yarmoshenko, I., Malinovsky, G., Vasilyev, A., \& Zhukovsky, M. (2015). Reconstruction of national distribution of indoor radon concentration in Russia using results of regional indoor radon measurement programs. J. Environ. Radioact., 150, 99-103.

21. Chissov, V. I., Starinsky, V. V., \& Petrova, G. V. (2010). Malignant neoplasm in Russia in 2008 (morbidity and mortality). Moscow: P. Herzen Moscow Oncology Research Institute (in Russian).

22. Chissov, V. I., Starinsky, V. V., \& Petrova, G. V. (2011) Malignant neoplasm in Russia in 2009 (morbidity and mortality). Moscow: P. Herzen Moscow Oncology Research Institute (in Russian).

23. Chissov, V. I., Starinsky, V. V., \& Petrova, G. V. (2012) Malignant neoplasm in Russia in 2010 (morbidity and mortality). Moscow: P. Herzen Moscow Oncology Research Institute (in Russian).

24. Chissov, V. I., Starinsky, V. V., \& Petrova, G. V. (2013) Malignant neoplasm in Russia in 2011 (morbidity and mortality). Moscow: P. Herzen Moscow Oncology Research Institute (in Russian).

25. Kaprin, A. D., Starinsky, V. V., \& Petrova, G. V. (2014). Malignant neoplasm in Russia in 2012 (morbidity and mortality). Moscow: P. Herzen Moscow Oncology Research Institute (in Russian).

26. GATS Russian Federation. (2009). Global Adult Tobacco Survey: Russian Federation Country Report, Russian Federation. Retrieved 24 November, 2015, from http://www.who.int/tobacco/surveillance/ en_tfi_gats_russian_countryreport.pdf. 